\title{
Community dentists finally approved for 2016 contract
}

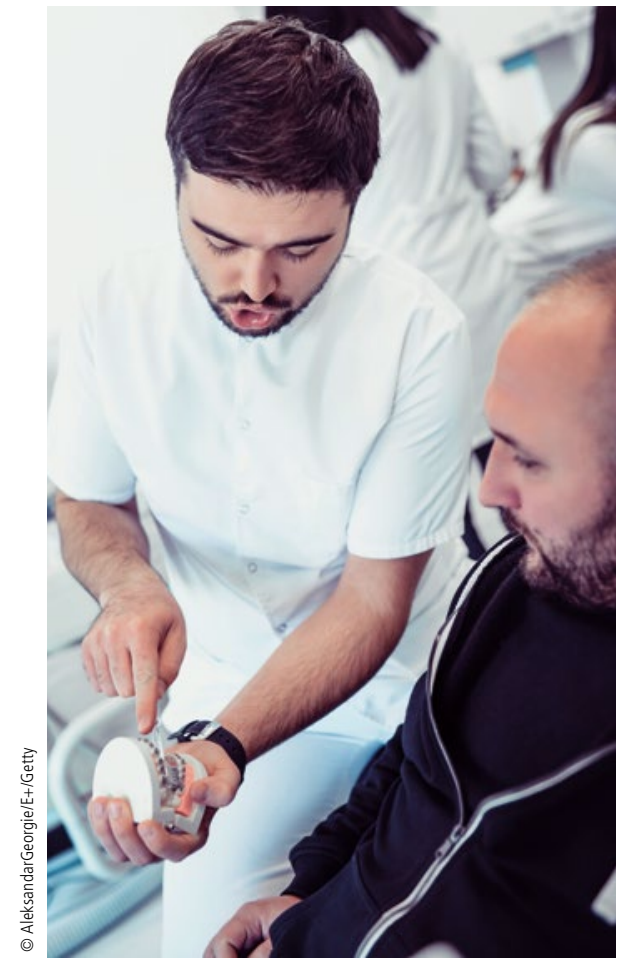

Community dentists in Northern Ireland have finally been granted approval to join the rest of their UK colleagues in working under a new contract agreed three years ago.

The political paralysis with the Northern Irish Assembly at Stormont has meant repeated delays to the process of implementing the 'new' working contract agreed in 2016.
Northern Ireland's community dentists were the last healthcare workers in the whole of the UK to be working to contracts drafted in the 1980s.

The service provides dental care for people of all ages across the province including children and adults with learning disabilities, patients with health problems, phobias, and those unable to leave their homes.

Despite a deal being reached for the whole UK, and funding allocated to local Trusts by the Department of Health in 2016, Stormont officials had refused to proceed to implement the contract without formal ministerial approval.

Following BDA pressure, permanent secretaries have finally agreed to rollout of the 'new' contract from April 2019.

The BDA welcomed the decision, saying that the vital role performed by the community dental service should never again be taken for granted.

Last year's Health and Social Care

Workforce Strategy $2026^{1}$ for Northern Ireland identified growing recruitment problems, and that a significant number of the most experienced community dentists were approaching retirement, with as much as $40 \%$ reported to be potentially retiring by 2025 .

The BDA said uncertainty over contracts and resource pressures had damaged morale in the service, with BDA surveys indicating
$47 \%$ of respondents rated their morale in their work as a dentist as being 'low' or 'very low'.

The new deal will see pay come into line with community colleagues in the rest of the UK, and will be backdated to 1 April 2015 .

Grainne Quinn, Chair of the BDA's Northern Ireland Salaried Dentists Committee, said: 'Our hard-working staff deserve the improved terms and conditions, and they have been very patient awaiting its implementation. We will be looking to Trusts to work with the Department to ensure all staff get their long-awaited back pay in a timely fashion.

'This has been a surreal experience. Since initial agreements in 2016, the BDA have been trying to get this contract implemented, but have been thwarted at all stages with first, no Minister present, and secondly, no government in place.

'Despite this, we pushed ahead looking at every opportunity to raise this issue with senior officials to enable us to get to completion this week. Paralysis at Stormont had left the care for thousands of vulnerable patients at risk. Finally, after a decade of negotiation, frustration and inertia we've got a result.'

\section{References}

1. Department of Health. Health and Social Care Workforce Strategy 2026: Delivering for Our People. 2018 Availale at https://www.health-ni.gov.uk/sites/default/files/ publications/health/hsc-workforce-strategy-2016.pdf (accessed April 2019).

\section{Threat of being sued worries $77 \%$ of dentists}

The threat of being sued by a patient is a source of stress and anxiety for almost $80 \%$ of dental professionals, according to a survey carried out recently by Dental Protection, an organisation offfering discretionary indeminty for dentists, doctors and healthcare professionals.

The organisation carried out a survey of its members in March 2019 in the run up to April - Stress Awareness Month and gathered responses from 1,129 UK dentists.

Results showed that nearly eight out of ten $(77 \%)$ of respondents admitted that the fear of being sued has caused them stress or anxiety.

Receiving a claim, a complaint, or being the subject of an investigation by the General Dental Council (GDC) can be a source of stress and anxiety for dental professionals.

Previous studies had suggested that healthcare professionals often did not seek help when they found themselves in such circumstances, so it was important to recognise the early signs and symptoms of stress and to seek help in order to avoid the negative impact that stress could have on a dentist's professional and personal life.

Raj Rattan, Dental Director at Dental Protection, said: 'Stress can impact on a dentist's health and practice in a number of ways. It can affect confidence, clinical judgement, morale and even lead to performance issues.

'Research confirms that high stress levels affect performance and increase the potential for adverse outcomes of error. These may in turn spark patient complaints and claims and a self-perpetuating vicious circle is established. Sustained periods of stress with poor coping strategies can lead to burnout.

'Modern life is full of challenges, stressors and pressures - and the dental profession is no exception. During Stress Awareness month, the organisation would like to encourage dentists to seek help and advice to manage the condition before it causes irreversible changes to health and well-being.' 